\title{
Improved seasonal prediction of UK regional precipitation using atmospheric circulation
}

Article

Accepted Version

Baker, L., Shaffrey, L. and Scaife, A. A. (2018) Improved seasonal prediction of UK regional precipitation using atmospheric circulation. International Journal of Climatology, 38 (S1). e437-e453. ISSN 0899-8418 doi:

https://doi.org/10.1002/joc.5382 Available at https://centaur.reading.ac.uk/73964/

It is advisable to refer to the publisher's version if you intend to cite from the work. See Guidance on citing.

Published version at: http://onlinelibrary.wiley.com/doi/10.1002/joc.5382/full

To link to this article DOI: http://dx.doi.org/10.1002/joc.5382

Publisher: John Wiley \& Sons

All outputs in CentAUR are protected by Intellectual Property Rights law, including copyright law. Copyright and IPR is retained by the creators or other copyright holders. Terms and conditions for use of this material are defined in the End User Agreement.

www.reading.ac.uk/centaur 
Central Archive at the University of Reading

Reading's research outputs online 


\title{
Improved seasonal prediction of UK regional precipitation using atmospheric circulation
}

\author{
L. H. Baker*1, L. C. Shaffrey ${ }^{1}$, and A. A. Scaife ${ }^{2}$ \\ ${ }^{1}$ NCAS Climate, Department of Meteorology, University of \\ Reading, Reading, UK \\ ${ }^{2}$ Met Office Hadley Centre, Exeter, UK
}

\begin{abstract}
*Correspondence to: Department of Meteorology, University of Reading, P.O. Box 243, Reading, RG6 6BB, UK. l.h.baker@reading.ac.uk
\end{abstract}

Keywords: precipitation, atmospheric circulation, seasonal forecasting, downscaling

Funding: LHB was supported by the NERC project IMPETUS (ref. NE/L010488/1). AAS was supported by the Joint DECC/Defra Met Office Hadley Centre Climate Programme (GA01101). 


\begin{abstract}
The aim of this study is to further our understanding of whether skilful seasonal forecasts of the large-scale atmospheric circulation can be downscaled to provide skilful seasonal forecasts of regional precipitation. A simple multiple linear regression model is developed to describe winter precipitation variability in nine UK regions. The model for each region is a linear combination of two mean sea-level pressure (MSLP)-based indices which are derived from the MSLP correlation patterns for precipitation in north-west Scotland and south-east England. The first index is a pressure dipole, similar to the North Atlantic Oscillation but shifted to the east; the second index is the MSLP anomaly centred over the UK. The multiple linear regression model describes up to $76 \%$ of the observed precipitation variability in each region, and gives higher correlations with precipitation than using either of the two indices alone. The Met Office's seasonal forecast system (GloSea5) is found to have significant skill in forecasting the two MSLP indices for the winter season, in forecasts initialised around the start of November. Applying the multiple linear regression model to the GloSea5 hindcasts is shown to give improved skill over the precipitation forecast by the GloSea5, with the largest improvement in Scotland.
\end{abstract}

\title{
1 Introduction
}

In recent years, the UK has experienced several extreme seasonal precipitation events, with instances of heavy rain leading to flooding in some regions (e.g. winter 2013-2014; Huntingford et al., 2014; Kendon and McCarthy, 2015; Muchan et al., 2015; Sibley et al., 2015), and periods of low precipitation leading to drought in others (e.g. the 2010-2012 drought; Kendon et al., 2013; Parry et al., 2013). The ability to forecast the risk of such events on seasonal timescales enables forward planning and the implementation of measures to mitigate the effects of these events on society.

There have been recent advances in the capability of seasonal forecasting for the North Atlantic and Europe. For example, Scaife et al. (2014) demonstrated that the GloSea5 system was able to skilfully forecast the wintertime North Atlantic Oscillation (NAO) from forecasts initialised around the start of November. However, it still remains extremely challenging to skilfully forecast the details of European weather on seasonal timescales.

One way to address this challenge is to utilise the observed relationships between the NAO and European weather. The NAO is often defined as the mean sea-level pressure (MSLP) difference between the Azores High and the Icelandic Low (e.g. Hurrell et al., 2003) and is a well-known driver of the weather in the UK and Northern Europe. When the NAO is positive, the North Atlantic jet is stronger, the UK and Northern Europe experience milder temperatures, stronger westerly winds, and more frequent passage of extratropical storms with associated precipitation. When the NAO is negative, the UK and Northern Europe experiences colder temperatures, with more frequent episodes of anticyclonic blocking, weaker winds and generally drier conditions.

This approach was adopted by Scaife et al. (2014), who showed that higher correlation skill scores are obtained for observed winter storminess, temperature and windspeed over much of Northern Europe when using the GloSea5 prediction of the NAO rather than the direct GloSea5 predictions of these weather 
variables. Similarly, Svensson et al. (2015) made use of the GloSea5 NAO forecast skill by including the NAO index as an input to a river flow model. They showed that using the NAO index from GloSea5 seasonal forecasts improved the skill of winter river flow forecasts for the UK. Palin et al. (2015) demonstrated that the GloSea5 winter NAO forecasts can be used to provide skilful forecasts of winter impacts on UK transport. Karpechko et al. (2015) found that skilful forecasts of Baltic Sea maximum ice extent could be obtained by using the GloSea5 winter NAO forecasts, which were more skilful than using explicit sea ice forecasts.

One key question is whether regional winter precipitation over the UK is primarily driven by the NAO or whether other patterns of atmospheric circulation, such as the East Atlantic Pattern (EAP), are also important. The EAP is characterised by a MSLP anomaly centred to the east of the central North Atlantic (Barnston and Livezey, 1987) and can affect the position of the North Atlantic jet (Woollings et al., 2010). The positive phase of the EAP is associated with a low pressure anomaly in the North Atlantic, with warmer temperatures in western Europe and increased precipitation to the south of, and collocated with, the low pressure centre. In the negative phase of the EAP, the high pressure anomaly in the North Atlantic is associated with a northward displacement of the jet and increased anticyclonic blocking in southwestern Europe.

The summer counterpart to the NAO, the summer NAO (SNAO) has a more northward position and smaller spatial extent, with MSLP centres approximately over Greenland and the UK (Folland et al., 2009). The positive phase of the SNAO is associated with high pressure over the UK and a stronger jet to the north, with the UK experiencing warmer, generally drier conditions; the negative phase has lower pressure over the UK and a weaker jet to the north, with the UK experiencing cooler, generally wetter conditions. In summer, the EAP pressure anomaly is weaker than in winter and is located further east, just to the west of the UK.

The relationship between regional precipitation and atmospheric circulation was investigated by Wilby et al. (1997), who showed that for winters with a strong positive NAO index, the west of Scotland had the strongest positive rainfall anomalies, while eastern England had negative rainfall anomalies. In contrast, in years with a strong negative NAO index, eastern England had positive rainfall anomalies while the west of Scotland had negative rainfall anomalies. Murphy and Washington (2001) found that in winter an index similar to the NAO (with slightly shifted centres) controlled the north-west/south-east precipitation gradient, while a second mode of atmospheric variability, with centres over Scotland and Madeira, controlled the precipitation amount over the UK. In summer a MSLP index with centres over Scotland and Greenland controlled the precipitation over the whole UK, but not the north-west/south-east gradient. Lavers et al. (2010) looked at the relationship between precipitation and river flow at ten observation stations across the UK, and different atmospheric fields. They found that the relative importance of the different quantities varied spatially and temporally. For stations in the north-western UK, winter precipitation is correlated with westerly winds and a MSLP dipole similar to the NAO. For stations in the south-east of England, winter precipitation is correlated with negative MSLP anomalies centred over the UK and westerly winds to the south. Similarly Folland and Woodcock (1986) used MSLP patterns to forecast half-monthly rainfall in different UK regions, and show a correlation 
of -0.80 between MSLP and precipitation in South-West England and South Wales in the first half of January. Folland et al. (2015) found a similarly strong correlation of -0.78 between the English Lowlands (the south-east of England) rainfall and MSLP anomalies centred over this region for the winter half-year.

Other studies used Lamb Weather Types (LWTs, Lamb, 1950) to categorise atmospheric circulation patterns and linked them with UK weather. Jones et al. (2014) studied relationships between UK precipitation and objectively defined LWTs (Jones et al., 2013). They found significant positive (negative) correlations between England and Wales total seasonal precipitation and the cyclonic (anticyclonic) LWTs in all four seasons. The LWTs can also be expressed in terms of the mean flow direction and strength and vorticity (Jenkinson and Collison, 1977). Osborn et al. (1999), Turnpenny et al. (2002) and Jones et al. (2013) looked at the relationship between regional precipitation and these circulation measures. They found that in south-east England the vorticity had the strongest link with the precipitation amount in all seasons, with high vorticity and cyclonic conditions generally leading to more precipitation. In north-west England and western Scotland the precipitation amount was most strongly influenced by flow strength, with stronger flows resulting in more precipitation.

The aim of this study is to further our understanding of whether skilful seasonal forecasts of the large-scale atmospheric circulation can be statistically downscaled to provide skilful seasonal forecasts of regional precipitation. This will be addressed by:

1. investigating the atmospheric circulation patterns associated with winter precipitation in different UK regions;

2. using these circulation patterns to produce a simple statistical downscaling method to describe UK regional precipitation variability and;

3. applying this downscaling methodology to the GloSea5 seasonal forecast data to provide improved seasonal forecasts of UK regional precipitation.

Section 2 describes the datasets used. In Section 3 the relationship between precipitation in different UK regions, and the relationship between regional precipitation and MSLP, are discussed. In Section 4 a multiple linear regression model is developed for UK regional precipitation, which is then applied to seasonal forecast data in Section 5 to test its capability at providing regional precipitation forecasts. Finally, Section 6 gives a summary of the results and a discussion of applications of this methodology.

\section{Methodology and data}

The precipitation observation data used in this study is the HadUKP UK regional precipitation series (Alexander and Jones, 2000). Data is available for 9 regions of coherent precipitation variability (as defined by Gregory et al. (1991); see maps in Fig. 1), for the period 1931 to present for Scotland and Northern Ireland, and the period 1873 to present for England and Wales. Only data between 1931 and 2012 is used in this study, for consistency between regions. The long period over which this data is available, and the fact that it is divided into predetermined coherent regions, makes it a suitable choice for this study. 
The precipitation data is derived from observed daily precipitation data from a selection of quality-controlled rainfall stations within each region, which are combined to give area average daily and monthly precipitation values for each region. Monthly means are used here, since daily data has been found to be too noisy in similar studies (Lavers et al., 2010, 2013). In addition to this regional precipitation dataset, the Met Office's UKCP09 gridded precipitation dataset (Met Office et al., 2017) is also used. This includes monthly mean precipitation observations on a high-resolution $5 \mathrm{~km} \times 5 \mathrm{~km}$ grid over the UK, and is available from January 1910 to December 2014.

The MSLP observation dataset used is HadSLP2r (Allan and Ansell, 2006). This is a gridded dataset created using marine and land observations, which are blended and interpolated onto a $5^{\circ} \times 5^{\circ}$ regular grid. The HadSLP2r dataset extends back to the year 1850, and therefore covers the period studied in this paper.

The seasonal hindcast data is from the Met Office Global Seasonal forecast system, GloSea5 (MacLachlan et al., 2015). This is a global ensemble forecast system with 24 ensemble members. The hindcast set covers the period winter 1992-1993 to winter 2011-2012, and is the same hindcast dataset as used by Scaife et al. (2014). Hindcasts were initialised on 25 October, 1 November and 9 November in each year, with eight members for each start date; members from the same start date differ from each other by applying a stochastic physics parameterisation. The model has a resolution of $0.83^{\circ}$ longitude by $0.55^{\circ}$ latitude, 85 levels in the vertical, with model top at $85 \mathrm{~km}$, and a relatively high-resolution ocean $\left(\sim 0.25^{\circ}\right.$ horizontally, 75 vertical levels $)$ with interactive sea-ice. For consistency with observed MSLP, the model MSLP fields have been regridded to the HadSLP2 $5^{\circ} \times 5^{\circ}$ grid. For comparison between GloSea 5 precipitation and the UKCP09 observed precipitation, the UKCP09 is regridded to the GloSea5 grid and a land-sea mask applied to remove points where at least $50 \%$ of the gridbox is ocean.

Throughout this paper 'winter' is defined as the average of December, January and February, and referred to as DJF, and 'summer' is defined as the average of June, July and August, and referred to as JJA. Individual winters are referred to by the year corresponding to the December at the start of the season (e.g. winter 2011-12 is referred to as winter 2011).

\section{Regional precipitation variability in the UK}

The aim of this section is to explore the relationships between precipitation in each UK region, and the associated atmospheric circulation patterns. The seasonal precipitation for winter and summer for each of the HadUKP regions is shown in Fig. 1 and Table 1. In both seasons, there is a clear north-west/southeast gradient in precipitation, with more precipitation received in the northwestern regions than the south-eastern regions. The Northern and Southern Scotland regions (NS and SS respectively) receive the most precipitation in both summer and winter, with more than double the amount in winter than received by South-East and Central England (SEE and CE respectively). SouthWest England (SWE) receives a large amount of precipitation in winter, but considerably less in summer. East Scotland (ES) is substantially drier than NS, despite their close locations. Regions in the east have similar precipitation 
totals in summer and winter, while regions in the west have more precipitation in winter.

To investigate the north-west/south-east gradient further, Figs. 2(a,c) show the winter and summer correlations between precipitation in NS and precipitation in each region, while Figs. 2(b,d) show correlations between precipitation in SEE and precipitation in each region; the correlations are given in detail in Table 1. These two regions were chosen since they are at opposite ends of the domain, and because the timeseries of precipitation in each of these regions are not significantly correlated in either season. NS is strongly correlated with SS in both seasons (Figures 2a and c), but the correlation rapidly weakens further to the south. NS also has a relatively low correlation with ES in both seasons, despite ES being directly to the east of NS. This is due to the so-called 'rain shadow' effect (Weston and Roy, 1994; Fowler et al., 2005; Svensson et al., 2015), whereby regions to the east of mountain ranges receive considerably less precipitation under westerly flow than occurs to the west. Correlations with SEE are generally stronger and more widespread than for NS (Figures 2b,d). The strongest correlations with SEE are seen in the two bordering regions (SWE and CE) while the weakest SEE correlations are with NS and SS. The summer correlations between regions are similar to the winter correlations. However, in summer there is more spatial coherence across the country than in winter, with stronger correlations seen in summer between more remote regions than in winter. The low correlations between regions at opposite ends of the UK might indicate that precipitation in each region has different atmospheric drivers.

Figure 3 shows correlation maps of winter mean MSLP with precipitation in each UK region. There are substantial differences in spatial patterns between north-western and south-eastern regions of the UK. The NS correlation pattern (Fig. 3a) has a north-south pressure dipole, and resembles the positive phase of the NAO but with centres shifted to the east. Over the UK, there is a strong meridional pressure gradient, corresponding to westerly wind anomalies. Periods with positive precipitation anomalies in NS are therefore associated with a stronger North Atlantic jet stream, stronger westerlies and the passage of more low pressure systems and associated fronts across the norther UK. Periods with negative precipitation anomalies in NS are associated with easterly wind anomalies over the UK, corresponding to a weaker or meandering North Atlantic jet stream, and typically associated with more frequent atmospheric blocking patterns. SS shows a similar correlation pattern to that of NS but with slightly weaker magnitude (Fig. 3b).

In contrast, the SEE correlation pattern (Fig. 3i) has a region of negative correlations, corresponding to a low pressure anomaly, centred over the UK. This resembles the EA pattern (Barnston and Livezey, 1987) but with the area of strongest correlation centred further to the east, over the UK. High precipitation anomalies in SEE therefore occur when there is a low pressure anomaly centred over the UK, with the jet passing roughly across the centre of the UK. Low precipitation anomalies in SEE are associated with a blocking pattern over the UK and western Europe. North-East England (NEE) and CE show similar correlation patterns to SEE (Figs. 3f and h), although the correlations are slightly weaker. The correlation patterns for Northern Ireland (NI) and NorthWest England (NWE) (Figs. 3d and e) have a north-south pressure dipole like NS, but shifted further south, meaning that the low pressure part sits partly over the UK, and the westerly wind anomalies are located over northern Spain. 


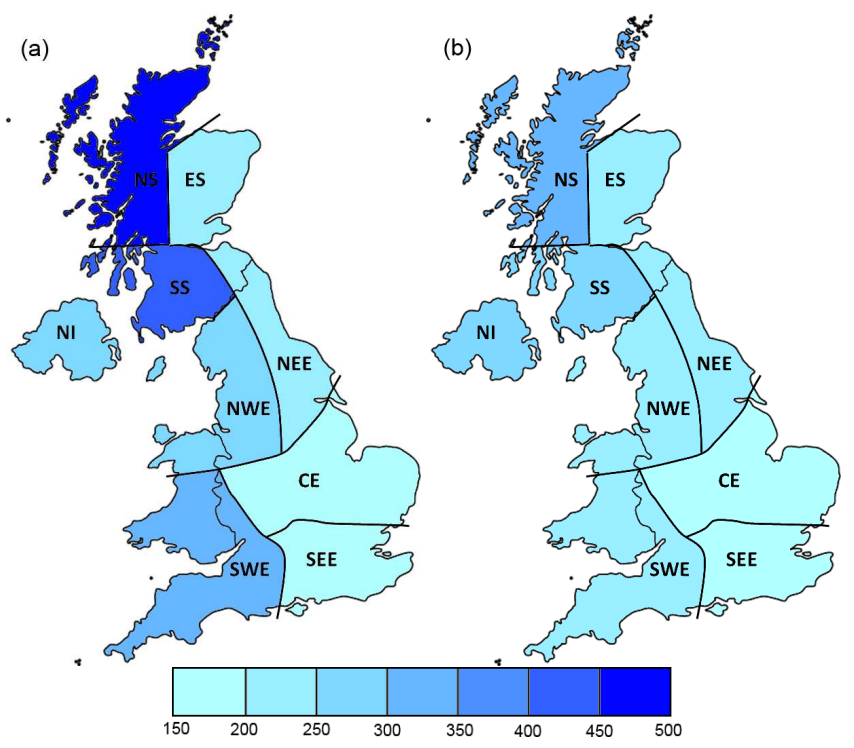

Figure 1: Maps of HadUKP observed regional precipitation, showing average total precipitation (in $\mathrm{mm}$ ) in each region in (a) winter and (b) summer, for the period 1931-2011.

Therefore NI and NWE have elements of both the NS and SEE correlation patterns. SWE has a similar correlation pattern to SEE (Fig. 3g) but with the low pressure centred a little further north, while ES (Fig. 3c) has generally weaker correlations, and the low centre further to the north-east.

Inspection of composites of the ten wettest and driest years for each region (not shown) show that these MSLP patterns are roughly symmetric for the wet and dry cases, with only small variations in the locations of high and low MSLP anomaly centres.

Equivalent correlation maps are shown for summer in Fig. 4. NS shows a region of low pressure centred to the north of the UK and west of Norway (Fig. 4a). All other regions show a MSLP dipole with high positive correlations over Greenland and negative correlations centred just to the east of the UK; this pattern resembles the SNAO (Folland et al., 2009).

The above results show that in both winter and summer, the seasonal-mean precipitation in regions in the north-west and south-east of the UK are not significantly correlated, and that they are associated with different atmospheric circulation patterns.

\section{Downscaling atmospheric drivers to estimate UK regional precipitation}

In this section the links between precipitation and MSLP circulation patterns discussed in Section 3 are used to derive a simple multiple linear regression model to estimate winter precipitation in each region based on historical observations. Only winter is considered here, since the aim is to derive a model that can be 

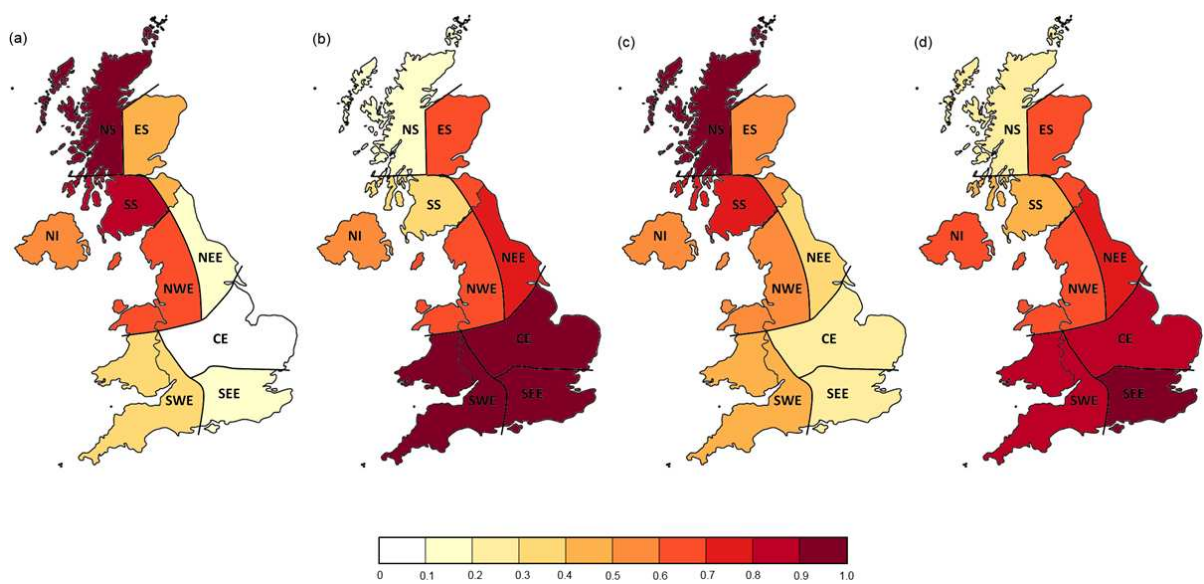

Figure 2: Maps showing seasonal correlations of HadUKP observed regional precipitation, for the period 1931-2011. Panels show correlations between each region and (a,c) NS, (b,d) SEE, in (a,b) DJF and (c,d) JJA.

developed for seasonal prediction, and currently the known skill of GloSea5 for the North Atlantic region is only in winter. The potential to develop a similar methodology for summer is discussed in Section 6.

Using the correlations discussed in Section 3, it is possible to derive a simple multiple linear regression model to estimate the winter precipitation in each UK region, making use of the fact that NS and SEE precipitation are uncorrelated and driven by different atmospheric patterns of variability. Informed by the MSLP correlation maps in Figs. 3a and i, two MSLP indices are constructed that represent these atmospheric patterns. For NS precipitation, the maximum correlation value is located in North Africa, at $35^{\circ} \mathrm{N}, 5^{\circ} \mathrm{W}$, and the minimum is over the ocean to the north of the UK, at $70^{\circ} \mathrm{N}, 5^{\circ} \mathrm{W}$. We construct the index MSLP $_{\mathrm{NSI}}$, defined as the standardised (i.e. centred about the time-mean value and divided by the standard deviation over the timeseries) MSLP difference between the southern point and the northern point (i.e. similar to the NAO index). For SEE, there is a strong negative correlation centred over the UK. We therefore construct a MSLP index based only on MSLP at this point. We define the index MSLP $\mathrm{UK}_{\mathrm{K}}$ as the standardised mean MSLP anomaly in a box centred over the UK $\left(50^{\circ} \mathrm{N}-60^{\circ} \mathrm{N}, 10^{\circ} \mathrm{W}-5^{\circ} \mathrm{E}\right)$. The correlation between the two


significant $(-0.06)$.

To construct the multiple linear regression model, a training period (19311991) is used, and a later period (1992-2011) is used to evaluate the model. Figure 5a shows the correlation between winter precipitation in each region and

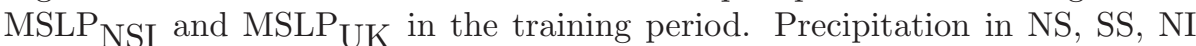
and NWE is significantly correlated with MSLP ${ }_{\text {NSI }}$ (blue bars), while precipitation in all regions except for NS is significantly correlated with MSLP $\mathrm{UK}_{\text {(green }}$ bars). The geographical distribution of these correlations is shown in Fig. 6 . The four regions where precipitation is significantly correlated with MSLP $\mathrm{NSI}$ are in the north-west of the UK, with the highest correlation in NS (Fig 6a). Correlations between precipitation and $\mathrm{MSLP}_{\mathrm{UK}}$ are larger in the south of the 

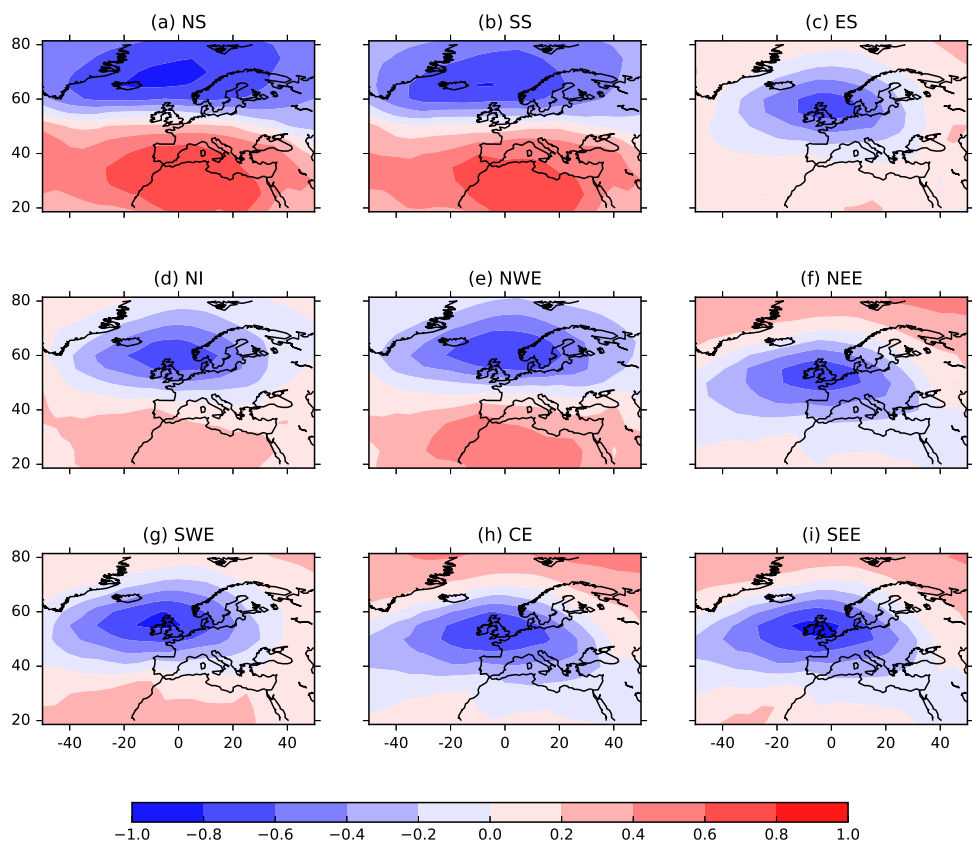

Figure 3: Maps of observed correlation between winter MSLP and winter precipitation in each of the HadUKP regions, for the period 1931-2011. 

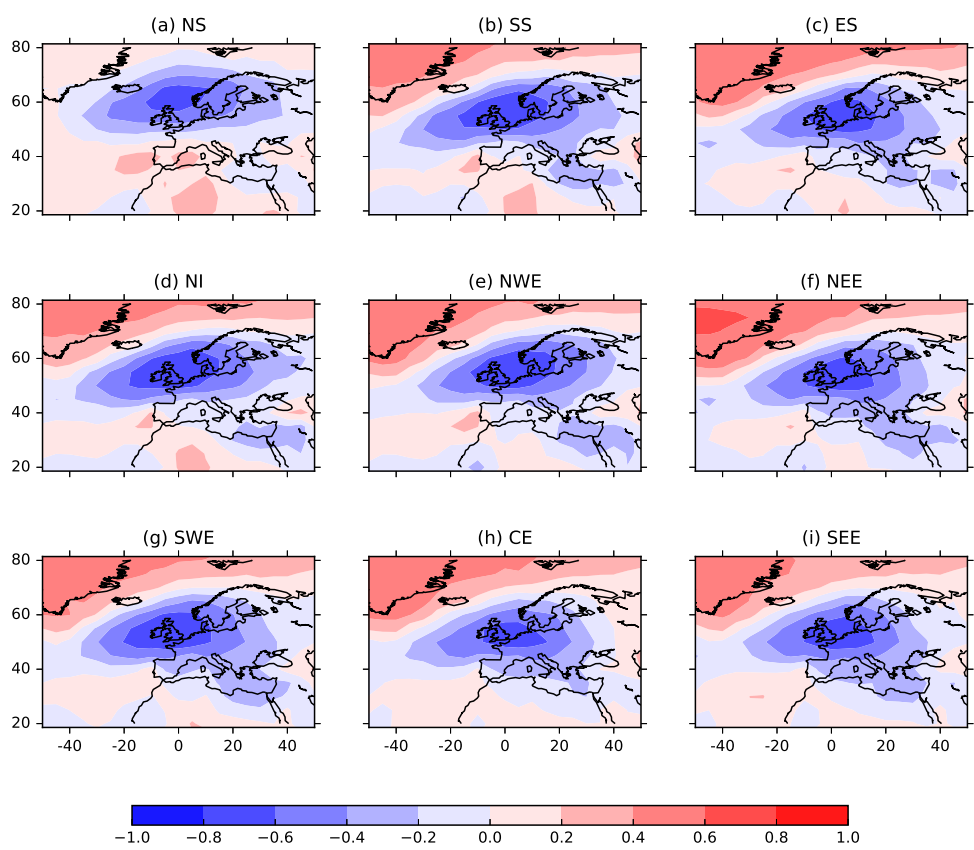

Figure 4: Maps of observed correlation between summer MSLP and precipitation in each of the HadUKP regions, for the period 1931-2011. 
UK, with the highest correlations in SEE and SWE. In all regions, the precipitation is significantly correlated with at least one of the two MSLP indices, and in three regions the precipitation is significantly correlated with both indices.

A multiple linear regression model for the estimated precipitation, $P_{\operatorname{lin} i}$, in each region $i$ is constructed using MSLP $_{\mathrm{UK}}$ and $\mathrm{MSLP}_{\mathrm{NSI}}$ as predictors. Thus for region $i$ :

$$
P_{\operatorname{lin} i}=\alpha_{i} \mathrm{MSLP}_{\mathrm{UK}}+\beta_{i} \mathrm{MSLP}_{\mathrm{NSI}}+c_{i} .
$$

Each region $i$ has a different set of regression coefficients $\alpha_{i}, \beta_{i}$ and $c_{i}$ which represent the relative importance of MSLP $_{\mathrm{UK}}$ and $\mathrm{MSLP}_{\mathrm{NSI}}$ as atmospheric drivers of precipitation in that region. The forward selection stepwise linear regression method is used. A significance criterion of $p<0.1$ is used for inclusion in the regression model: if $p>0.1$ for one of the MSLP indices then the corresponding regression coefficient is 0 . The regression coefficients for each region are shown in Table 2. Here the standardised MSLP indices are used; that is, anomalies are computed which are normalised by the standard deviation of the index over the training period. $P_{\operatorname{lin} i}$ is therefore an estimate of the standardised precipitation anomaly, which can be scaled by the standard deviation of the observed precipitation timeseries for each region, and recentred about the mean, to give an actual precipitation estimate. Since the coefficients are for the precipitation anomaly, the term $c_{i}=0$. For correlation scores this choice of standardisation makes no difference. The impact of detrending the MSLP ${ }_{\mathrm{NSI}}$, MSLP $_{U K}$ and precipitation timeseries was found to make almost no difference to the results (correlations within 0.01), so the non-detrended values are used.

For each region the correlation between $P_{\operatorname{lin}_{i}}$ and the observed precipitation is shown in Fig. 5a (purple bars). To evaluate the derived precipitation against observed precipitation, the Spearman rank correlation is used in preference to the Pearson correlation, as this avoids making assumptions about linearity, and deals better with outliers (Wilks, 1995). Using the Pearson correlation gives generally similar results. The correlations between $P_{\operatorname{lin}_{i}}$ and observed precipitation are significant in all regions. The highest correlations are in SEE and SWE, with the lowest correlations in ES and NEE. In all regions apart from ES and NEE, this method explains more than $50 \%$ of the precipitation variance (i.e. the correlation $r \geq 0.71$ ), while in SEE more than $75 \%$ of variance is explained $(r \geq 0.87)$. Fig. $6 \mathrm{c}$ shows that the highest correlations are obtained for regions in the north-west and south of the country, with north-eastern regions having the lowest correlations.

To evaluate the simple multiple linear regression model, the coefficients derived for the 1931-1991 training period were applied to observed MSLP data for the test period 1992-2011, and the results evaluated against regional precipitation for this later period. Timeseries of the observed and derived precipitation for three sample regions are shown in Fig. 7. In NS (Fig. 7a) there is very good agreement between observed and derived precipitation, and in particular the precipitation extremes are well captured. In NWE (Fig. 7b), where precipitation is controlled by both pressure indices relatively equally, the extremes are again well captured, but there are a few years where the derived precipitation does not match the observed precipitation. A similarly good correspondence between observed and derived precipitation is seen for CE (Fig. 7c), but again there are a few years where the derived precipitation does not match the observed. The years with poor correspondence between derived and 
observed precipitation tend to be those where the precipitation is close to the mean value, which suggests that the model may not perform so well when the driving circulation patterns are weak. The correlations for the test period are shown in Fig. 5b. These are similar to the correlations for the training period (Fig. 5a). The good agreement between the downscaled and observed precipitation for the independent evaluation period suggest that the multiple linear regression model is robust, and is not over-fitted to the training dataset. Repeating the evaluation of the multiple regression model on other 20-year sub-periods (1932-1951, 1952-1971 and 1972-1991) also give similar correlations to those for the full training period. In regions NI and NWE, there is a difference in the relative importance of the two pressure indices between the training period and the test period: in the training period precipitation in these regions has a higher correlation with $\mathrm{MSLP}_{\mathrm{UK}}$ than $\mathrm{MSLP}_{\mathrm{NSI}}$, while in the test period the correlation with MSLP ${ }_{\text {NSI }}$ is higher (compare Fig. 5a and b). This emphasizes the need for a long training period that is independent from the test period.

The same methodology can be applied to the UKCP09 gridded precipitation data. A multiple linear regression model based on the two pressure indices can be derived for each grid point, over the training period 1931-1991. As for the regional precipitation, this leads to the strongest correlations between observed and derived precipitation in the south of England and the north-west of Scotland, with slightly lower correlations in the north-east of the country (not shown). The observed MSLP-precipitation relationships derived for each grid point are used in Section 5.2 to derive forecasts of precipitation on these scales.

\section{Seasonal precipitation forecasts using the mul- tiple linear regression model}

The aim of this section is to evaluate seasonal hindcasts of UK regional precipitation obtained by applying the multiple linear regression model developed in Section 4 to GloSea5 hindcasts of MSLP.

\subsection{Evaluation of GloSea5}

The current GloSea5 system has been shown to have good skill in forecasting the wintertime NAO from forecasts initialised around the start of November, with a correlation skill score of 0.62 for the period 1992-2011 (Scaife et al., 2014). Less has been said about the skill in forecasting precipitation, although MacLachlan et al. (2015) showed that there was little skill in raw model output for Northern Europe for DJF upper and lower terciles of precipitation (their Figure 13). Figure 8(a) shows a map of the correlation skill for the ensemble mean precipitation from GloSea5 evaluated against the UKCP09 gridded precipitation observations (regridded first to the GloSea5 grid). There are a few gridboxes with high skill (correlations exceeding 0.5 ), mostly in south Wales and moderate (but not significant) skill in some gridboxes in western Scotland. In general the grid-point skill within the HadUKP regions is coherent, although in the SWE region this is not true, as South Wales has higher skill than further south. Most of the eastern parts of the UK have low or no skill (correlations less than 0 in some places). These results should, however be taken with caution 

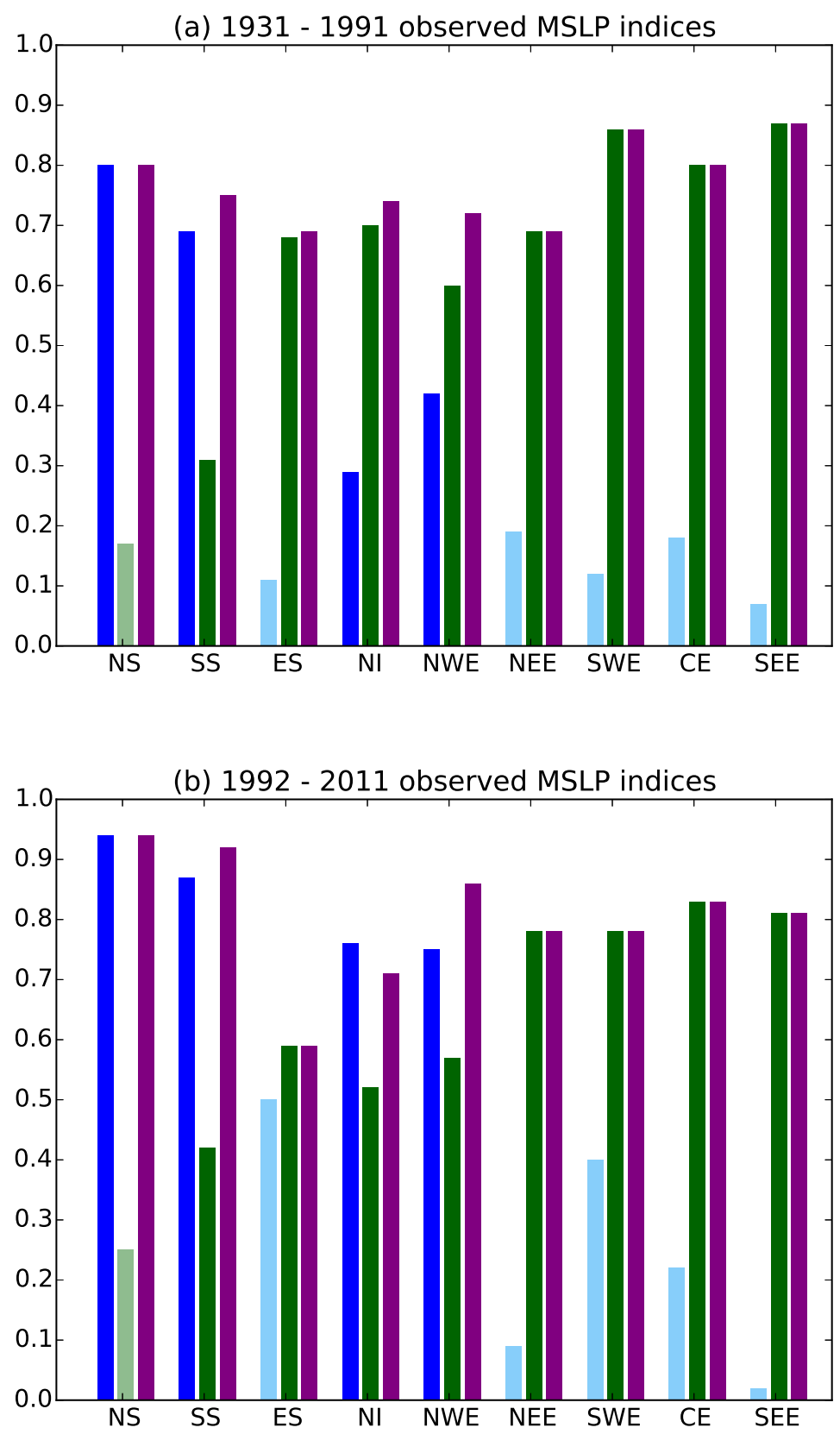

Figure 5: Absolute value of Spearman rank correlations between observed winter regional precipitation and the two pressure indices MSLP $_{\mathrm{NSI}}$ (blue), MSLP $_{\mathrm{UK}}$ (green) and derived precipitation $P_{\text {lin }}$ (purple) for (a) the training period (19311991) and (b) the test period (1992-2011). Correlations that are not significant $(p>0.1)$ in the training period (and therefore correspond to indices not used in the construction of $\left.P_{\text {lin }}\right)$ are shown in pale blue/green. 

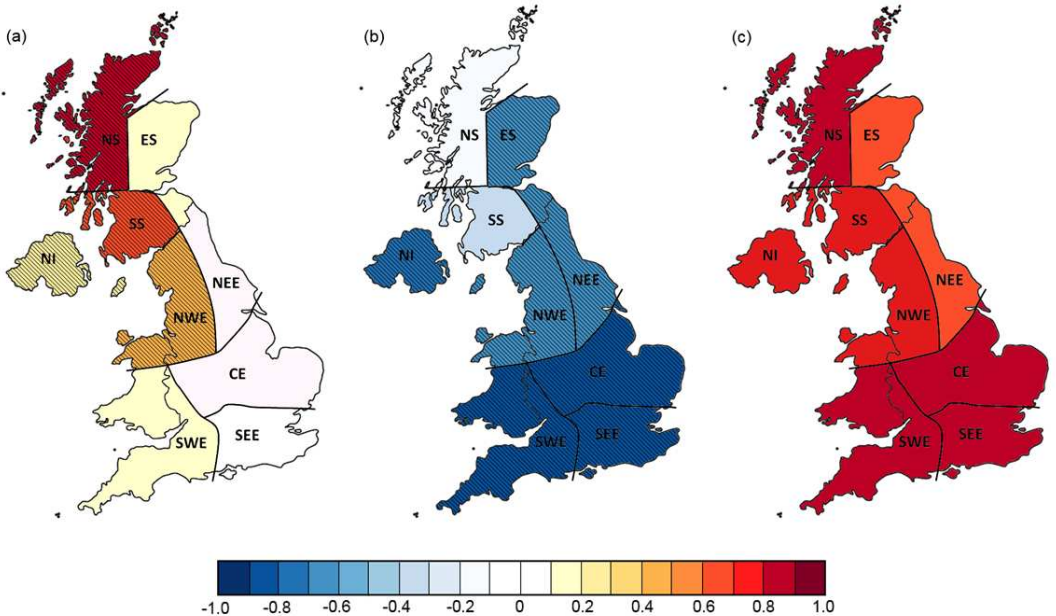

Figure 6: Correlation between winter regional precipitation and (a) MSLP ${ }_{\mathrm{NSI}}$, (b) MSLP ${ }_{\mathrm{UK}}$, and (c) $P_{\text {lin }}$ for observations in the training period (1931-1991). In (a,b) correlations that are significant at the $90 \%$ level are overlayed with hatched lines; in (c) all correlations are significant so hatching is omitted for clarity.

since data output from models such as seasonal forecast models is not designed to be evaluated on the grid-point scale (e.g. Lander and Hoskins, 1997).

Figure 9 shows a spatial map of the skill of the GloSea5 ensemble mean in directly forecasting DJF MSLP, as compared to the HadSLP2 observation dataset, over a domain covering the North Atlantic and Europe. Regions over the UK and to the north and south, including the MSLP $_{\text {NSI }}$ centres, have reasonable skill, with correlation values between 0.4 and 0.6. The model correlation skill scores for the two indices defined in Section 4 are 0.56 for MSLP NSI $_{\text {, and } 0.50}$

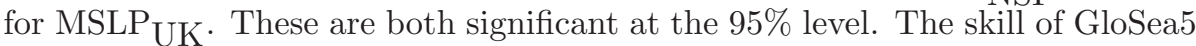
in forecasting DJF atmospheric circulation variability in the North Atlantic is therefore not restricted to the NAO, but also includes other modes of variability.

It is also important to understand whether the GloSea5 forecast system can spatially represent the atmospheric drivers of UK regional precipitation.

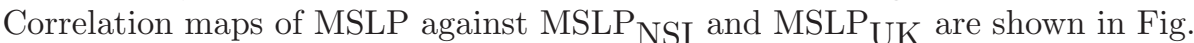
10, both for the observations for the full period 1931-2011 and for GloSea5 for the period 1992-2011. As expected, the observed correlation pattern for MSLP $_{\text {NSI }}$ (Fig. 10a) shows a dipole structure, and looks almost identical to the NS precipitation correlation pattern (Fig. 3a). The equivalent correlation map for GloSea5 is very similar (Fig. 3b), although the southern centre of the dipole is slightly weaker in GloSea5 than the observations. The observed correlation

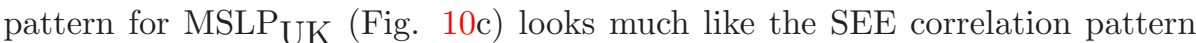
(Fig. 3i) with the signs reversed. The equivalent correlation map for GloSea5 again strongly resembles the observed pattern (Fig. 10d). The fact that these correlation maps are similar for GloSea5 and for the observations indicates that these MSLP indices correspond to the same atmospheric circulation patterns. 

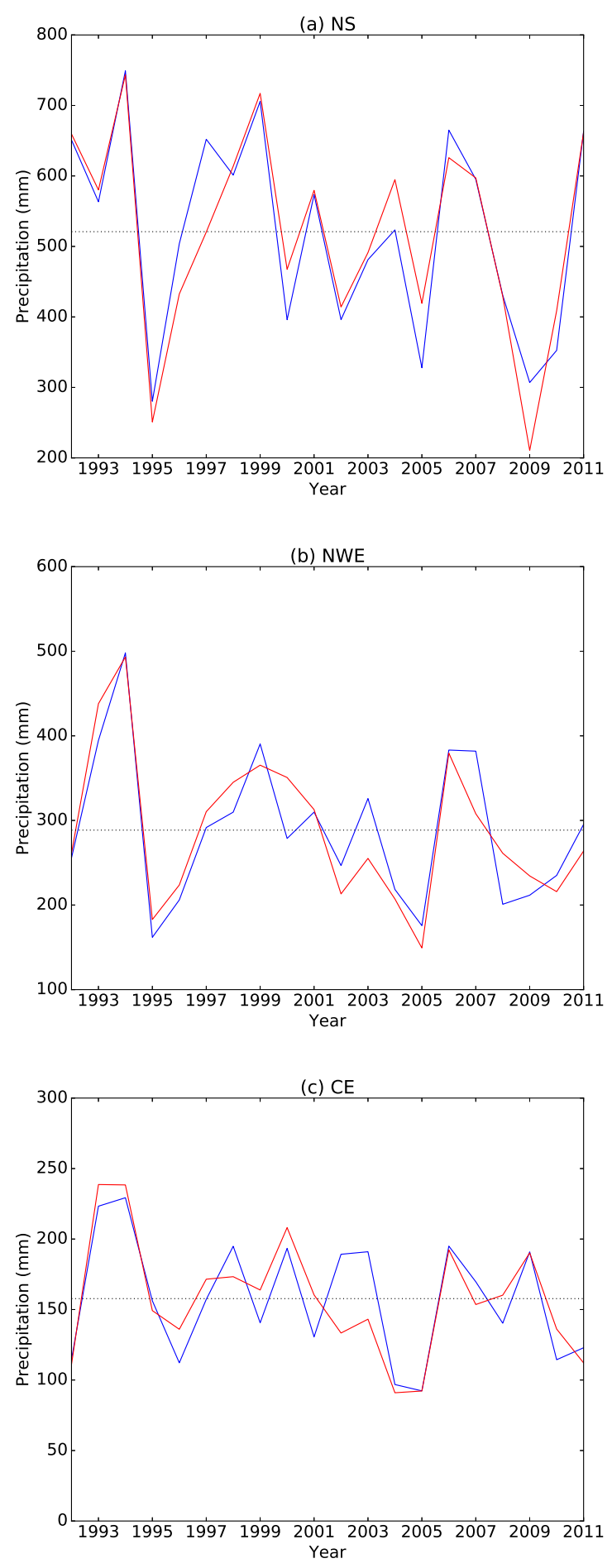

Figure 7: Time series of DJF observed precipitation (blue lines) and precipitation derived using the multiple linear regression model applied to HadSLP2 observed pressure indices (red lines), for the period 1992-2011. Panels show precipitation in (a) Northern Scotland, (b) North-West England and (c) Central England. The dotted black line marks the time-mean observed precipitation. 
(a) GloSea5 precipitation

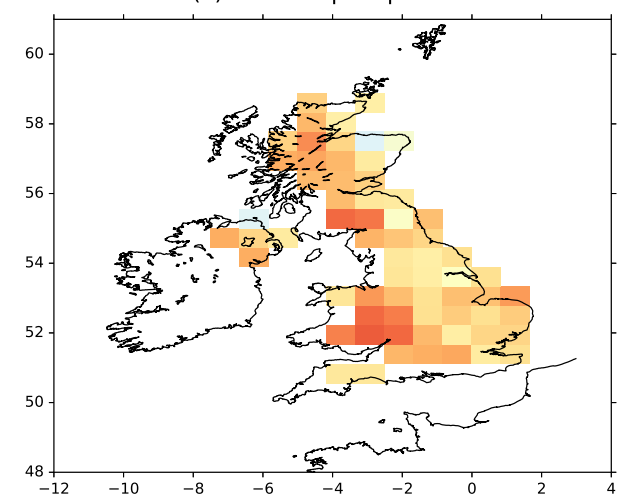

(b) Derived precipitation on GloSea5 grid

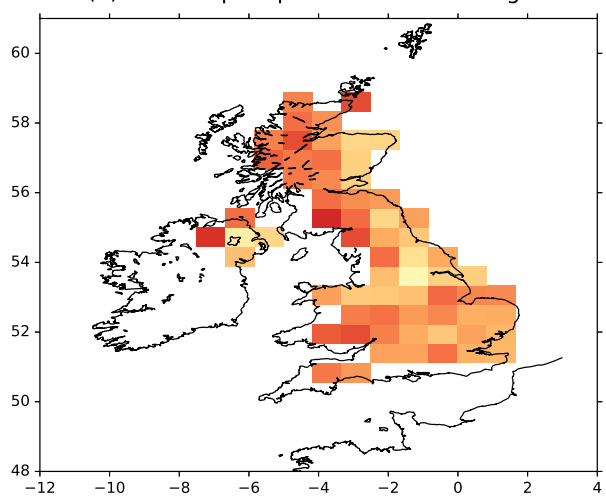

(c) Derived precipitation
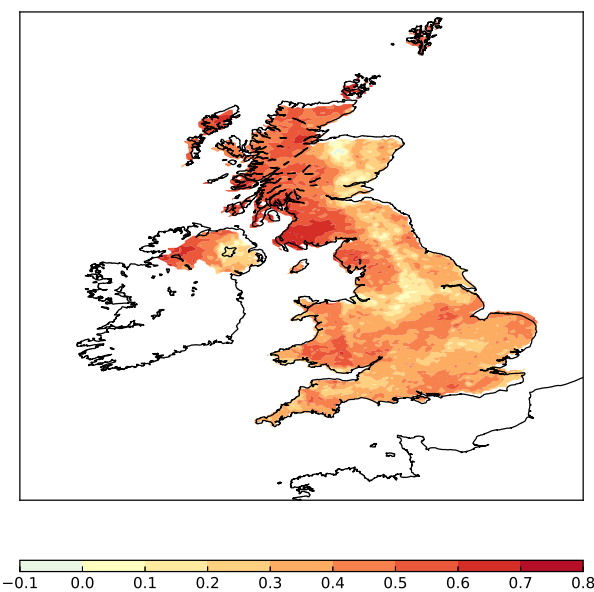

Figure 8: Spearman rank correlation scores for winter precipitation for the period 1992-2011. (a) Correlation skill for ensemble mean precipitation from GloSea5 at each grid-box compared with the UKCP09 observed precipitation regridded to the GloSea5 model grid. (b,c) Correlation skill for ensemble mean precipitation derived from GloSea5 MSLP indices using the multiple linear regression model compared with the UKCP09 observed precipitation. In (b) the correlation map is regridded to the Glafea5 grid for comparison with (a); (c) is on the native UKCP09 5km grid. 


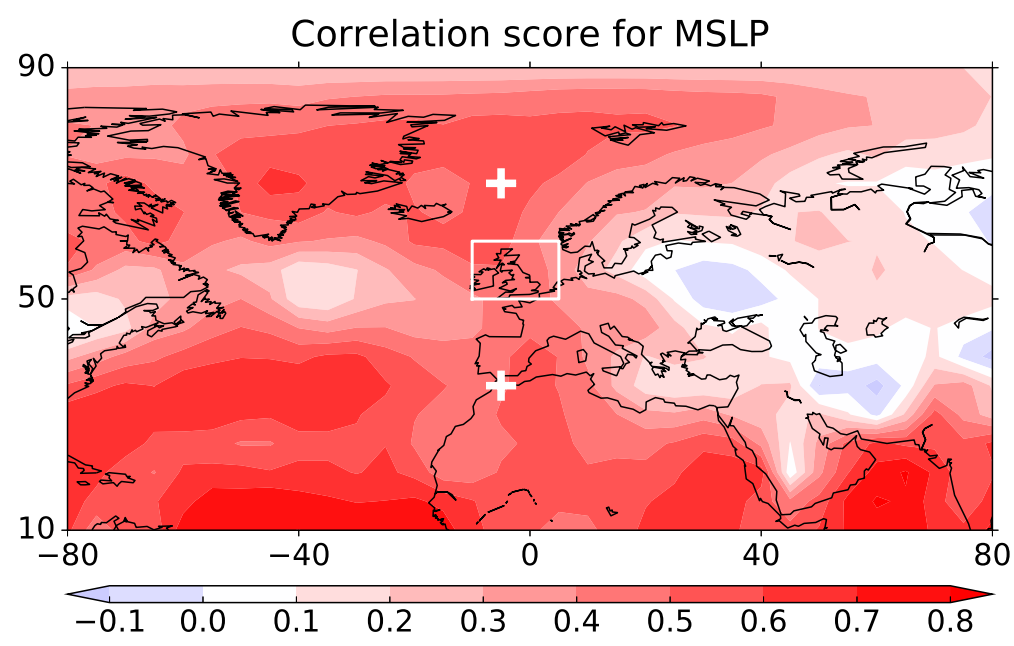

Figure 9: Correlation skill score between GloSea5 ensemble mean MSLP and observed MSLP for the hindcast period 1992-2011. '+' symbols indicate the locations of the MSLP ${ }_{\mathrm{NSI}}$ centres, while the rectangular box indicates the averaging area for $\mathrm{MSLP}_{\mathrm{UK}}$. 

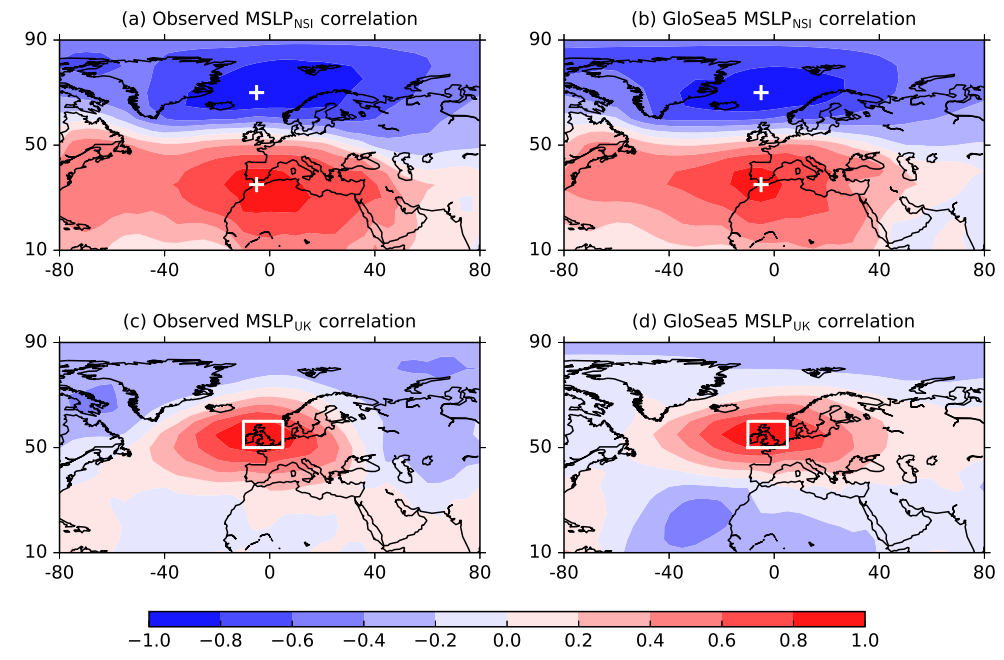

Figure 10: Point-based correlation between MSLP fields and (a, b) MSLP NSI and (c, d) UK MSLP, for (a, c) observations for the period 1931-2011 and (b, d) GloSea5 for the period 1992-2011. In (b,d) the map shows the mean of the individual ensemble members' correlations between MSLP and the respective indices. '+' symbols in $(\mathrm{a}, \mathrm{b})$ indicate the $\mathrm{MSLP}_{\mathrm{NSI}}$ centres, while the rectangle in $(\mathrm{c}, \mathrm{d})$ indicates the averaging area for $\mathrm{MSLP}_{\mathrm{UK}}$. 


\subsection{Forecasting precipitation using the multiple linear re- gression model based on observations}

The multiple linear regression model was applied to the GloSea5 hindcasts of the two pressure indices. The model was applied to each ensemble member individually. In this section the skill for the ensemble mean is discussed. In Section 5.3 a discussion of how this method can be used to produce a probabilistic forecast is given.

Figure 11 shows the skill obtained in forecasting precipitation for each region by applying the multiple linear regression model to the $\mathrm{MSLP}_{\mathrm{NSI}}$ and MSLP $_{U K}$ indices obtained from the GloSea5 hindcast data for DJF, from forecasts initialised around the start of November. The highest skill is obtained for NS, which has a correlation skill score of 0.64. CE and SS also have high correlation scores above 0.5. NI and NWE have reasonable correlation scores above 0.4 , which are significant at the $90 \%$ level. The remaining three regions have lower skill, with the lowest correlation skill score seen in SWE.

The high skill in forecasting NS and SS precipitation is due to the model's relatively high skill in forecasting the $\mathrm{MSLP}_{\mathrm{NSI}}$, and the high correlation between this pressure index and precipitation in these regions (Fig. 12). The fact that good skill is obtained in the north-west of the UK is consistent with the findings of Svensson et al. (2015) that this region is strongly influenced by the NAO, which is a similar MSLP dipole index to MSLP ${ }_{\mathrm{NSI}}$.

In regions NI and NWE, significant skill in forecasting precipitation is also obtained (Fig. 11). It can be seen from Fig. 12, however, that in these regions, the correlation between GloSea5 forecast MSLP NSI $_{\text {and observed precipitation }}$ is higher than the correlation between the estimated precipitation $P_{\text {lin }}$ and observed precipitation. This is related to the fact that, in these two regions, in the test period the observed precipitation is more strongly related to observed MSLP $_{\text {NSI }}$ while in the training period MSLP $\mathrm{UK}_{\mathrm{K}}$ is more important (as discussed at the end of Section 4). For more general periods it would therefore

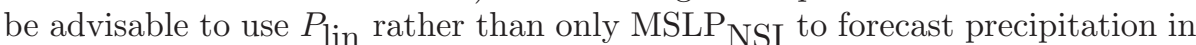
these regions.

The remaining regions are those where precipitation is driven by MSLP $\mathrm{UK}_{\text {. }}$ CE has relatively high skill (0.51) compared to the remaining four regions. ES and NEE are the two regions with the lowest correlations in the observations in the training period, so this is not unexpected. In contrast, SEE and SWE have relatively low correlation skill scores, but have the highest correlations in the observations between the actual precipitation and predicted precipitation $P_{\text {lin }}$, and therefore high potential predictability. This is partly due to the lower skill in the model forecast of MSLP $\mathrm{UK}_{\mathrm{K}}$ compared with the skill for MSLP $\mathrm{MSI}_{\text {. Therefore }}$ future improvements in GloSea5's ability to represent variability in MSLP $\mathrm{UK}_{\mathrm{K}}$ would lead to improvements in precipitation forecasts using this method.

Using relationships derived for the UKCP09 gridded precipitation data, it is possible to apply this methodology to generate high-resolution gridded precipitation forecasts. Figure 8c shows the correlation scores obtained using this method to forecast precipitation at each grid point in the UK. This shows a similar pattern of skill to that for regional precipitation, with the highest skill seen in the north-west of the UK. In this case Southern Scotland has areas with the highest correlation skill. There are some differences in detail; in particular there is a narrow band of regions with lower skill extending southwards from 
north-east Scotland; this is collocated with high orography, and may be a result of limited or less reliable observations in these regions. These results are also shown regridded to the GloSea5 grid in Fig. 8b, for comparison with the GloSea5 direct precipitation output. This downscaling method gives an improvement in skill over the GloSea5 direct precipitation output in most gridboxes. There are a few gridboxes, in Northern Ireland and the West of England where the derived precipitation gives slightly worse results than GloSea5 direct precipitation output. However, it should be noted that the $5 \mathrm{~km}$ precipitation forecast obtained using this method are potentially much more useful for streamflow modelling, as it will allow distinction between river basins not possible with the much coarser resolution GloSea5 precipitation forecast.

\subsection{Generating a probabilistic forecast for regional pre- cipitation}

We have focussed on correlation skill so far because unlike probabilistic measures like reliability, the correlation is robust to post-processing changes to the ensemble spread. Nevertheless, probabilistic forecasts are useful to represent uncertainty and so in this section we demonstrate how a well calibrated probabilistic forecast for UK regional precipitation can be produced. Scaife et al. (2014) noted that, while the winter NAO prediction skill is high, the magnitude of the signal in the ensemble mean is much smaller than the interannual variability of the observations. Furthermore, the forecast skill is higher than would be expected given the size of the ensemble mean signal and the ensemble spread. To address this issue, Eade et al. (2014) defined a quantity, which they termed the ratio of predictable components (RPC), to give an estimate of the ratio of the 'predictability of the real world' to the 'predictability of the model'. The 'predictability of the real world' is estimated by the ensemble mean correlation coefficient with the observations, while the 'predictability of the model' is estimated from the standard deviation of the ensemble mean divided by the standard deviation of ensemble members. This quantity should be 1 for a perfect forecast system. Eade et al. (2014) developed a method to correct the ensemble mean signal and ensemble members accordingly, to make RPC equal to unity. This method alters the ensemble mean variance according to the correlation skill, and adjusts the ensemble members such that the ensemble variance about the ensemble mean is equal to the unpredictable noise of the observations. The correction does not affect correlation skill and is described in full in Eade et al. (2014). The correction method can be applied in real-time using ensemble information from a hindcast period. The RPC and the correction method are described in more detail in Appendix B. Here we show results both with and without this correction by applying it to the GloSea5 predictions of MSLP $_{\mathrm{NSI}}$ and $\mathrm{MSLP}_{\mathrm{UK}}$ before they are used to infer rainfall. The RPC values for MSLP $\mathrm{NSI}_{\text {and }}$ MSLP $\mathrm{UK}_{\mathrm{K}}$ are 2.07 and 1.48, respectively.

The observed and estimated precipitation timeseries for two regions (NS and CE) obtained for the 20-year test period are shown in Figure 13. Although the correlation skill is high for NS precipitation (0.64, Fig. 11), Fig. 13a shows that the magnitude of the signal in the ensemble mean predicted precipitation is much smaller than that of the observed precipitation variability, by a factor of 5 . The ensemble is also overdispersed; the ensemble spread is larger than the observed extreme precipitation values in the timeseries. Similarly the magnitude of the 

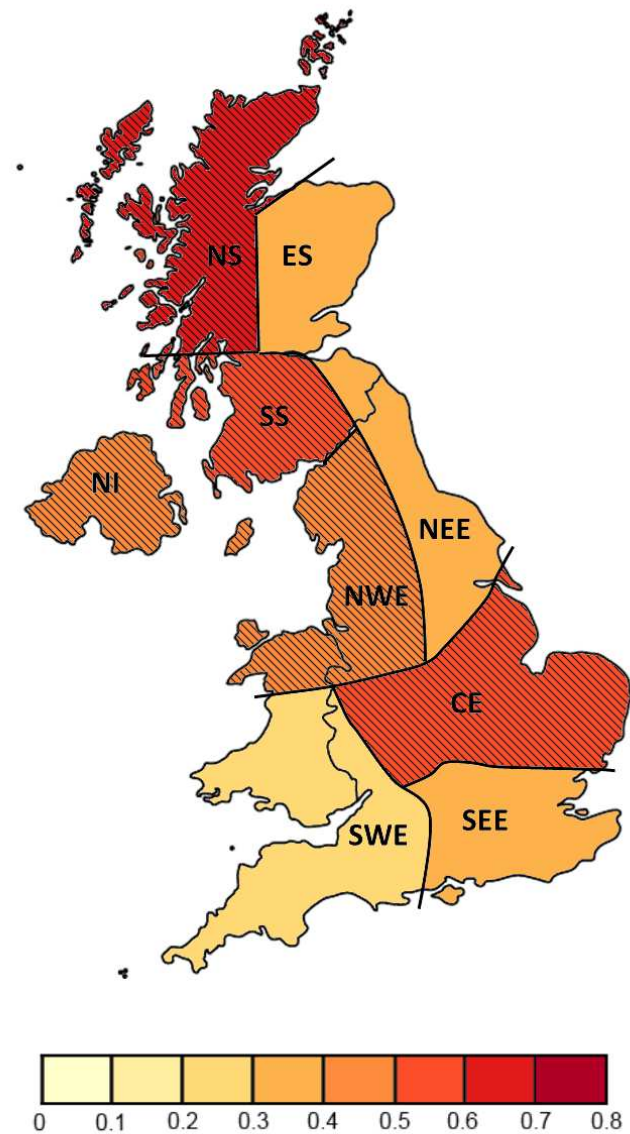

Figure 11: Spearman rank correlation skill for predicting winter precipitation in each of the HadUKP regions using the multiple linear regression model applied to GloSea5 MSLP fields for the period 1992-2011. Correlations that are significant at the $90 \%$ level are overlayed with hatched lines. 


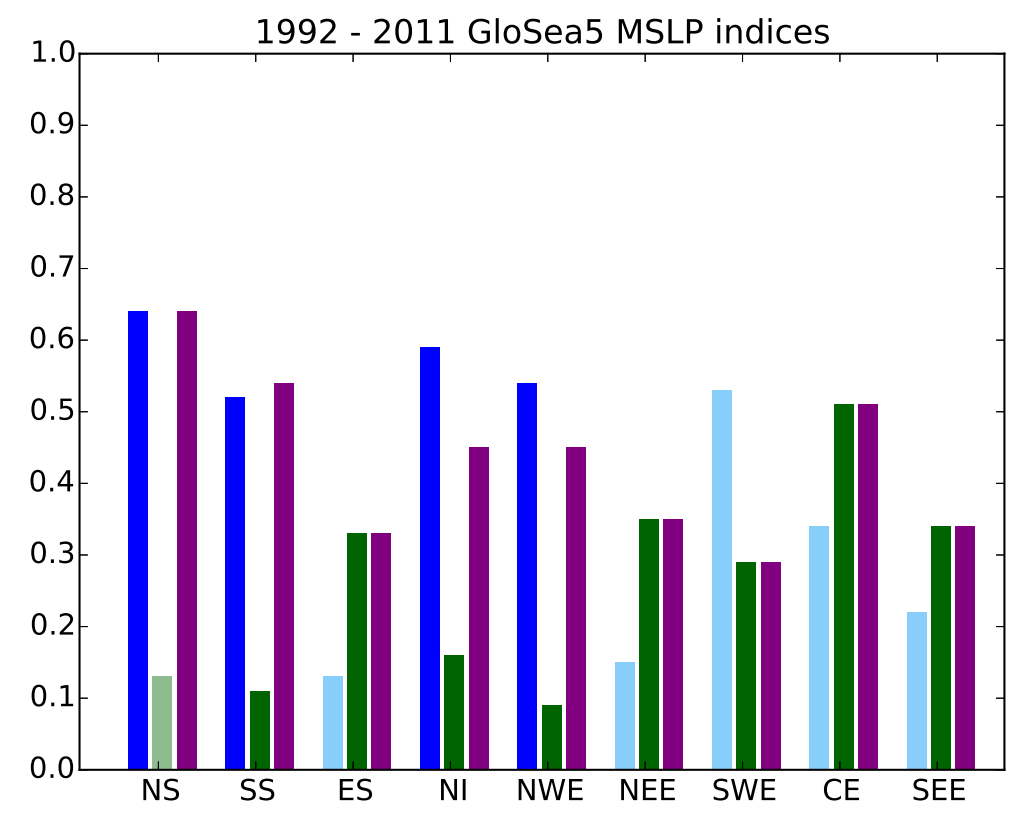

Figure 12: Absolute value of Spearman rank correlations between observed winter regional precipitation and the two pressure indices MSLP $_{\text {NSI }}$ (blue), MSLP $_{\text {UK }}$ (green) and derived precipitation $P_{\text {lin }}$ (purple) from GloSea5 hindcasts, over the period 1992-2011. Correlations that are not significant $(p>0.1)$ in the training period (and therefore correspond to indices not used in the construction of $\left.P_{\text {lin }}\right)$ are shown in pale blue/green. 
signal of the CE ensemble mean precipitation estimates (Fig. 13b) is a factor of 3 smaller than the observed precipitation variability in this region, and the ensemble spread is again large. Similar features are also seen for precipitation in the remaining seven regions (not shown). Equivalent series produced using the RPC-corrected pressure indices are shown in Figures 13c and d. For NS (Fig. 13c) using the RPC correction gives an ensemble mean signal magnitude around double that obtained using the uncorrected values (Fig. 13a). The ensemble spread is also smaller in this case. In particular, in winters 1994 and 2011, the ensemble forecast confidently predicts the high precipitation anomalies observed. The RPC correction has less effect on CE precipitation predictions (Fig. 13d) and other regions where precipitation is driven mainly by MSLP $_{U K}$. This is due to the lower correlation skill for $\mathrm{MSLP}_{U K}$, which means that the inflation of the ensemble mean signal is smaller. Nevertheless, the ensemble mean signal for $\mathrm{CE}$ precipitation is increased by a factor of 1.5 by the RPC correction, and gives smaller ensemble variance than obtained using the uncorrected values (Fig. 13b). Finally, it is interesting to note that in winter 2011, both the observations and ensemble mean show a relatively large positive precipitation anomaly in NS (Figs. 13a and c) and a relatively large negative precipitation anomaly in $\mathrm{CE}$ (Figs. 13b and d). This is an example of how this method can predict regional differences in precipitation.

To give a probabilistic evaluation of the ensemble forecasts' ability to predict higher or lower than average precipitation, the Brier skill score is used (see Appendix A for more details). Brier skill scores for each region are shown in Table 3, for both the uncorrected and RPC-corrected ensembles. In all regions except for ES the BSS is greater than zero, indicating that the ensemble forecast has more skill than climatology. In general the RPC-corrected ensemble gives better Brier skill scores than the uncorrected ensemble. However, in the regions with low skill (ES and SWE) the RPC correction does not improve the Brier skill scores. The five regions with significant correlation skill (Fig. 11) have high Brier skill scores, while those with lowest correlation skill have lower Brier skill scores.

\section{Discussion and conclusions}

The aim of this study was to determine whether skilful seasonal forecasts of the large-scale atmospheric circulation can be downscaled to provide skilful seasonal forecasts of UK regional precipitation.

Precipitation in the UK has a north-west/south-east gradient, in terms of both the total amount of precipitation and the main atmospheric drivers of precipitation. This gradient is stronger in winter than in summer. In winter, there are two distinct atmospheric circulation patterns associated with precipitation variability in the north-west regions and in the south-east regions. Precipitation in the north-west is associated with a MSLP dipole with centres to the

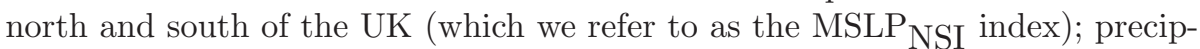
itation in the south-east is associated with a MSLP anomaly centred over the UK (which we refer to as the MSLP $\mathrm{UK}_{\mathrm{K}}$ index). These modes of variability resemble eastward-shifted versions of the NAO and the EA Pattern, respectively. GloSea5 seasonal hindcasts were found to skilfully represent both these modes of variability in winter in forecasts initialised around the start of November. 

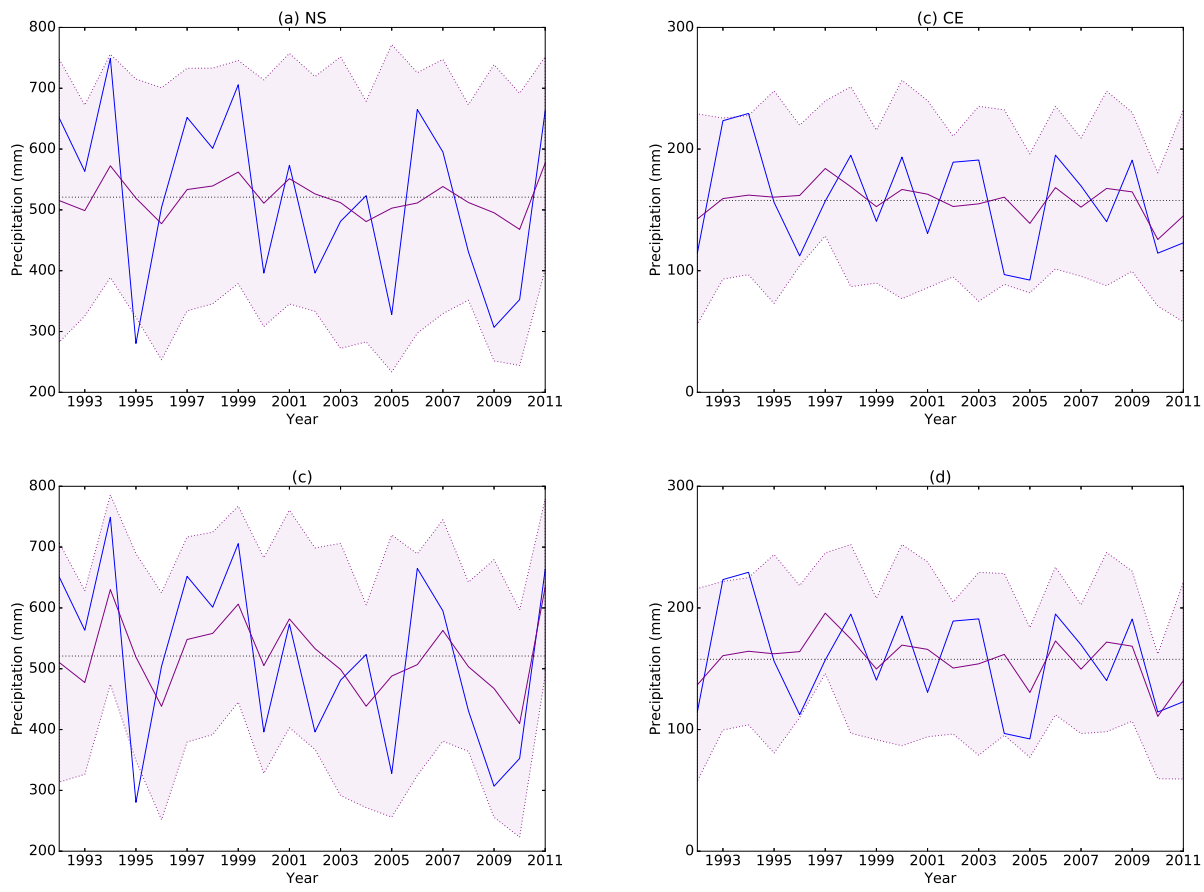

Figure 13: Timeseries of observed and estimated winter precipitation (in $\mathrm{mm}$ ) in regions (a,c) Northern Scotland and (b,d) Central England. Blue lines show the observed precipitation, purple lines show the ensemble mean estimate precipitation, with shading and dotted purple lines indicating plus and minus two standard deviations of the ensemble member estimates. The dotted black line marks the time-mean observed precipitation. (a) and (b) show timeseries obtained using the unadjusted ensemble forecasts of MSLP NSI $_{\text {and }}$ MSLP $_{\mathrm{UK}}$; (c) and (d) show timeseries obtained using the RPC-corrected ensemble forecasts of $\mathrm{MSLP}_{\mathrm{NSI}}$ and $\mathrm{MSLP}_{\mathrm{UK}}$. 
The skill of GloSea5 in winter is therefore not restricted to the NAO, but also extends to MSLP variability centred over the UK.

A simple multiple linear regression model has been developed to describe the variability of winter precipitation in each UK region, using indices based on these two circulation patterns. This multiple linear regression model describes between 50 and $76 \%$ of observed precipitation variability in each region. Applying this multiple linear regression model to GloSea5 seasonal hindcasts of winter MSLP leads to more skilful forecasts than simply using precipitation forecasts directly from GloSea5. The correlation skill is particularly high for north-western regions of the UK (0.64), in which precipitation is driven primar-

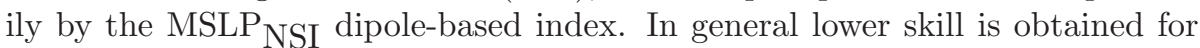
south-eastern regions, which are more strongly influenced by the MSLP ${ }_{U K}$ index, although Central England shows promising forecast correlation skill (0.51). The generally lower skill in England than in Scotland may be because GloSea5 has lower skill for MSLP $_{U K}$ than for MSLP ${ }_{N S I}$, therefore improvements in forecasting MSLP over the UK could lead to skilful seasonal forecasts of winter precipitation for all UK regions.

The downscaling methodology developed in this study has also be applied to the UKCP09 $5 \mathrm{~km}$ gridded precipitation data, which gives broadly similar results to the regional analysis. Comparison between the derived precipitation and GloSea5 direct precipitation output showed that this downscaling technique gives better correlation skill than simply using the direct GloSea5 precipitation output. In addition, the $5 \mathrm{~km}$ gridded precipitation forecast produced using this method are potentially useful for streamflow modelling, as they allow distinction between river basins not possible with the much coarser resolution GloSea5 precipitation forecasts. Due to the constraints of computational cost, seasonal forecast models cannot currently be run at higher resolution, and certainly they will not be run operationally at horizontal resolutions close to $5 \mathrm{~km}$ in the near future. Even if run at kilometre-scale resolutions, biases in the model mean state such as positioning of the North Atlantic jet would make it difficult to use direct precipitation output from these models on seasonal timescales, so downscaling methods such as the one used in this paper would still be useful.

A probabilistic ensemble forecast for regional UK precipitation can be made using this methodology by applying the multiple linear regression model to MSLP $_{\text {UK }}$ than for MSLP ${ }_{\text {NSI }}$ forecast by individual GloSea5 ensemble member. However, post-processing of the ensemble forecasts must be performed in order to correct for the low signal-to-noise ratio of the ensemble. The RPC correction used here is one such post-processing technique. Applying this correction to the forecast pressure indices gives a larger signal in the ensemble mean regional precipitation forecasts, and smaller ensemble spread, or more confident forecasts. Brier skill scores show that the ensemble of derived precipitation forecasts using this method has skill higher than climatology in most regions.

This multiple linear regression approach could also be applicable to decadal forecasting and future climate projections. In these lower-resolution models, regions with different precipitation drivers could well be contained within one gridbox. The sub-grid-scale or near-grid-scale variability means that it is difficult to use precipitation directly from these models to provide forecasts or to draw conclusions about future changes in precipitation. In particular, the larger interannual variability of precipitation received by north-western UK regions compared to those in the south-east means that variability in precipitation 
in the north-western regions dominate variability in the UK total precipitation. As shown in this study, precipitation in the south-east and north-west regions is uncorrelated. Therefore any forecast or projection based on a UK-average precipitation contains little information about precipitation in south-eastern UK regions. This has implications for forecasts or future projections of drought, to which the south-east is more vulnerable than the north-west (Folland et al., 2015). Using the multiple linear regression model, however, provides information about each region separately. One consideration for using this method in this context would be how much the relationship between atmospheric circulation and regional precipitation can be assumed to be stationary over longer timescales.

The method used in this study was designed to utilise known skill of the GloSea5 model at forecasting the wintertime NAO and circulation described by MSLP. If other fields such as vorticity, wind strength and wind direction can be forecast with similar levels of skill, then a similar method could be developed based on the Jenkinson indices (Jenkinson and Collison, 1977), utilising the relationships between these and regional precipitation found by Jones et al. (2014). Future model developments will lead to further increases in forecasting skill for atmospheric circulation patterns, both due to higher model resolution and larger ensemble sizes. This increased skill could be utilised in more complex downscaling methods, perhaps using the above-mentioned fields in addition to MSLP. In addition, furthering our understanding of the processes that underlie modes of atmospheric variability such as the NAO is essential for improving seasonal predictions and capturing the relationships with patterns of precipitation. This includes external processes such as ocean-atmosphere coupling (e.g. Kushnir, 1994) and internal atmospheric processes such as eddy-mean flow interactions (e.g. Wallace and Lau, 1985).

This study has focused on winter only for building the multiple linear regression model. However a similar approach can also be used for summer. Based on the correlation patterns in Fig. 4, two MSLP indices can be identified to model regional summer precipitation variability: the first index is a representation of the SNAO, defined using the pressure difference between a Greenland box $\left(70^{\circ} \mathrm{W}-45^{\circ} \mathrm{W}, 70^{\circ} \mathrm{N}-85^{\circ} \mathrm{N}\right)$ and a UK box (defined as for winter); the second index is the pressure at $\left(5^{\circ} \mathrm{W}, 60^{\circ} \mathrm{N}\right)$. Constructing a multiple linear regression model with observations of these two indices gives correlations with observed regional summer precipitation of between 0.7 and 0.8 , so this model explains more than about $50 \%$ of the precipitation variability in each region. In future seasonal forecast models with more skilful representation of summer atmospheric circulation, this method could be useful in forecasting summer precipitation as well as winter.

\section{Acknowledgements}

LHB was supported by the NERC project IMPETUS (ref. NE/L010488/1). AAS was supported by the Joint DECC/Defra Met Office Hadley Centre Climate Programme (GA01101). We thank the two annoymous reviewers for providing helpful comments and suggestions on the manuscript. 

671 by

\section{A The Brier skill score}

In Section 5.3 the Brier skill score is used to evaluate the probabilistic skill of the forecasts at forecasting higher or lower than average precipitation. Following (Jolliffe and Stephenson, 2003), the Brier skill score is defined as

$$
\mathrm{BSS}=1-\frac{B}{B_{\text {ref }}},
$$

where $B$ is Brier score $B$, defined as

$$
B=\frac{1}{n} \sum_{j=1}^{n} f_{j}-o_{j}
$$

$n$ is the number of years, $f_{j}$ is the forecast probability of the event in year $j$, and $o_{j}$ is equal to 1 if the event occurred and 0 if not. In this case the event is the occurrence of higher (or lower) than average precipitation in a given region. The forecast probability $f_{j}$ is calculated by taking the average of all ensemble members' forecasts of the event occurring (either 1 or 0 for each ensemble member). $B_{\text {ref }}$ is the climatology, in this case 0.5 since higher (lower) than average precipitation occurs $50 \%$ of the time.

Brier skill score values greater than 0 indicate that the ensemble system is more skilful than climatology; negative values indicate poorer skill than climatology.

\section{B The ratio of predictable components (RPC) and RPC correction}

In Section 5.3 the RPC correction is used. The RPC gives an estimate of the ratio of the 'predictability of the real world' to the 'predictability of the model' (Eade et al., 2014). The predictable component of the observations $\left(\mathrm{PC}_{\mathrm{obs}}\right)$ is defined as the correlation $r$ between the ensemble mean and observations, given by

$$
\mathrm{PC}_{\mathrm{obs}}=r=\frac{\sum_{j=1}^{n}\left(\overline{x_{j}}-\hat{x}\right)\left(y_{j}-\hat{y}\right)}{\sqrt{\sum_{j=1}^{n}\left(\overline{x_{j}}-\hat{x}\right)^{2} \sum_{j=1}^{n}\left(y_{j}-\hat{y}\right)^{2}}},
$$

where $\overline{x_{j}}$ and $y_{j}$ are the ensemble mean and observation (respectively) in year $j$, and $\hat{x}$ and $\hat{y}$ are the time-means of these quantities over $n$ years. The predictable component of the model $\left(\mathrm{PC}_{\mathrm{mod}}\right)$ is defined as the ratio of the ensemble mean standard deviation to the average ensemble member standard deviation, given by

$$
\mathrm{PC}_{\bmod }=\sqrt{\frac{\sigma_{\bar{x}}^{2}}{\frac{1}{m} \sum_{i=1}^{m} \sigma_{x_{i}}^{2}}}
$$

where $m$ is the number of ensemble members, $x_{i}$ is ensemble member $i$ and $\sigma_{x}$ represents the standard deviation over time of a quantity $x$. The RPC is then defined as the ratio

$$
\mathrm{RPC}=\frac{\mathrm{PC}_{\mathrm{obs}}}{\mathrm{PC}_{\mathrm{mod}}}
$$


$\mathrm{RPC}$ can have any value, but if the model predictability accurately reflects the observed predictability then $\mathrm{RPC}=1$. Values of $\mathrm{RPC}$ greater than one indicate an overdispersive system; positive values lower than one indicate underdispersion; and negative values indicate that there is no skill.

The RPC correction developed by Eade et al. (2014) adjusts the ensemble mean and ensemble members such that the $\mathrm{RPC}=1$. The ensemble mean is adjusted so that its variance is equal to the predictable part of the observed variance: $\mathrm{PC}_{\mathrm{obs}}^{2}=r^{2} \sigma_{y}^{2}$. The adjusted ensemble mean ${\overline{x_{j}}}^{\prime}$ in year $j$ is given by

$$
{\overline{x_{j}}}^{\prime}=\left(\overline{x_{j}}-\hat{x}\right) \frac{\sigma_{y} r}{\sigma_{\bar{x}}}+\hat{x},
$$

where $\sigma_{y}$ is the standard deviation of the observations. The ensemble members are then recentred about the adjusted mean and their variance adjusted to be equal to the variance of the unpredictable noise part of the observations: $\left(1-r^{2}\right) \sigma_{y}^{2}$. The adjusted ensemble member $i$ at time $j, x_{i j}^{\prime}$, is given by

$$
x_{i j}^{\prime}=\left(x_{i j}-\hat{x}\right) \frac{\sigma_{y} \sqrt{\left(1-r^{2}\right)}}{\sigma_{\text {mem } j}}+{\overline{x_{j}}}^{\prime}
$$

where $\sigma_{\mathrm{mem}_{j}}$ is the standard deviation of the ensemble members about the ensemble mean at time $j$. Full details can be found in Eade et al. (2014).

\section{References}

Alexander L, Jones P. 2000. Updated precipitation series for the UK and discussion of recent extremes. Atmos. Sci. Let. 1(2): 142-150, doi:10.1006/asle. 2000.0016 .

Allan R, Ansell T. 2006. A new globally complete monthly historical gridded mean sea level pressure dataset (hadslp2): 1850-2004. Journal of Climate 19(22): 5816-5842, doi:10.1175/JCLI3937.1.

Barnston AG, Livezey RE. 1987. Classification, seasonality and persistence of low-frequency atmospheric circulation patterns. Mon. Weather Rev. 115: $1083-1126$.

Eade R, Smith D, Scaife A, Wallace E, Dunstone N, Hermanson L, Robinson N. 2014. Do seasonal-to-decadal climate predictions underestimate the predictability of the real world? Geophysical research letters 41(15): 5620-5628, doi:10.1002/2014GL061146.

Folland C, Hannaford J, Bloomfield J, Kendon M, Svensson C, Marchant B, Prior J, Wallace E. 2015. Multi-annual droughts in the English Lowlands: a review of their characteristics and climate drivers in the winter half-year. Hydrology and Earth System Sciences 19(5): 2353-2375, doi: 10.5194/hess-19-2353-2015.

Folland CK, Knight J, Linderholm HW, Fereday D, Ineson S, Hurrell JW. 2009. The summer north atlantic oscillation: past, present, and future. Journal of Climate 22(5): 1082-1103, doi:10.1175/2008JCLI2459.1. 
Folland CK, Woodcock A. 1986. Experimental monthly long-range forecasts for the United Kingdom. part I: Description of the forecasting system. Met. Mag. 115: $301-318$.

Fowler H, Ekström M, Kilsby C, Jones P. 2005. New estimates of future changes in extreme rainfall across the uk using regional climate model integrations. 1. assessment of control climate. Journal of Hydrology 300(1): 212-233.

Gregory J, Jones P, Wigley T. 1991. Precipitation in Britain: an analysis of area-average data updated to 1989. Int. J. Climatol 11(3): 331-345.

Huntingford C, Marsh T, Scaife AA, Kendon EJ, Hannaford J, Kay AL, Lockwood M, Prudhomme C, Reynard NS, Parry S, Lowe JA, Screen JA, Ward HC, Roberts M, Stott PA, Bell VA, Bailey M, Jenkins A, Legg T, Otto FEL, Massey N, Schaller N, Slingo J, Allen MR. 2014. Potential influences on the United Kingdom's floods of winter 2013/14. Nature Climate Change 4(9): 769-777, doi:10.1038/nclimate2314.

Hurrell J, Kushner Y, Ottersen G, Visbeck M. 2003. The North Atlantic oscillation: climatic significance and environmental impact. In: An overview of the North Atlantic oscillation, Hurrell J (ed), AGU, pp. 1-35.

Jenkinson A, Collison F. 1977. An initial climatology of gales over the North Sea. Synoptic Climatology Branch Memorandum (62). Meteorological Office, Bracknell.

Jolliffe IT, Stephenson DB. 2003. Forecast verification. Wiley. Retrieved 6 September 2017, from http://www . myilibrary . com?ID=27190.

Jones PD, Harpham C, Briffa KR. 2013. Lamb weather types derived from reanalysis products. International Journal of Climatology 33(5): 1129-1139, doi:10.1002/joc.3498, URL http://dx.doi.org/10.1002/joc. 3498.

Jones PD, Osborn TJ, Harpham C, Briffa KR. 2014. The development of Lamb weather types: from subjective analysis of weather charts to objective approaches using reanalyses. Weather 69(5): 128-132, doi:10.1002/wea.2255, URL http://dx.doi.org/10.1002/wea. 2255.

Karpechko AY, Peterson KA, Scaife AA, Vainio J, Gregow H. 2015. Skilful seasonal predictions of Baltic sea ice cover. Environmental Research Letters 10(044007).

Kendon M, Marsh T, Parry S. 2013. The 2010-2012 drought in England and Wales. Weather 68(4): 88-95.

Kendon M, McCarthy M. 2015. The UK's wet and stormy winter of 2013/2014. Weather 70(2): 40-47.

Kushnir Y. 1994. Interdecadal variations in north atlantic sea surface temperature and associated atmospheric conditions. Journal of Climate 7(1): 141157. 
Lamb HH. 1950. Types and spells of weather around the year in the British Isles : Annual trends, seasonal structure of the year, singularities. Quarterly Journal of the Royal Meteorological Society 76(330): 393-429, doi:10.1002/ qj.49707633005, URL http://dx.doi.org/10.1002/qj . 49707633005.

Lander J, Hoskins B. 1997. Believable scales and parameterizations in a spectral transform model. Monthly weather review 125(2): 292-303.

Lavers D, Prudhomme C, Hannah DM. 2010. Large-scale climate, precipitation and british river flows: Identifying hydroclimatological connections and dynamics. Journal of Hydrology 395(3): 242-255, doi:10.1016/j.jhydrol.2010.10. 036 .

Lavers D, Prudhomme C, Hannah DM. 2013. European precipitation connections with large-scale mean sea-level pressure (mslp) fields. Hydrological Sciences Journal 58(2): 310-327, doi:10.1080/02626667.2012.754545.

MacLachlan C, Arribas A, Peterson K, Maidens A, Fereday D, Scaife A, Gordon M, Vellinga M, Williams A, Comer R, Camp J, Xavier P, Madec G. 2015. Global seasonal forecast system version 5 (GloSea5): a high-resolution seasonal forecast system. Quarterly Journal of the Royal Meteorological Society 141: 1072-1084, doi:10.1002/qj.2396.

Met Office, Hollis D, McCarthy M. 2017. UKCP09: Met Office gridded and regional land surface climate observation datasets. Centre for Environmental Data Analysis. 15 September 2017.

Muchan K, Lewis M, Hannaford J, Parry S. 2015. The winter storms of 2013/2014 in the UK: hydrological responses and impacts. Weather 70(2): $55-61$.

Murphy SJ, Washington R. 2001. United Kingdom and Ireland precipitation variability and the North Atlantic sea-level pressure field. International Journal of Climatology 21(8): 939-959, doi:10.1002/joc.670.

Osborn TJ, Conway D, Hulme M, Gregory JM, Jones PD. 1999. Air flow influences on local climate: observed and simulated mean relationships for the United Kingdom. Climate Research 13(3): 173-191.

Palin EJ, Scaife AA, Wallace E, Pope EC, Arribas A, Brookshaw A. 2015. Skilful seasonal forecasts of winter disruption to the UK transport system. J. Appl. Meteor. Climatol doi:10.1175/JAMC-D-15-0102.1.

Parry S, Marsh T, Kendon M. 2013. 2012: from drought to floods in England and Wales. Weather 68(10): 268-274.

Scaife A, Arribas A, Blockley E, Brookshaw A, Clark R, Dunstone N, Eade R, Fereday D, Folland C, Gordon M, Hermanson L, Knight JR, Lea DJ, MacLachlan C, Maidens A, Martin M, Peterson AK, Smith D, Vellinga M, Wallace E, Waters J, Williams A. 2014. Skillful long-range prediction of European and North American winters. Geophysical Research Letters 41(7): 25142519, doi:10.1002/2014GL059637. 
Table 1: Average total precipitation $(\mathrm{mm})$ in winter and summer seasons, along with regional correlation with NS and SEE regional precipitation in the two seasons, for HadUKP regions in years 1931-2012. Correlations in bold are significant at the $95 \%$ level, based on a two-tailed t-test.

\begin{tabular}{lcccccc}
\hline Region & $\begin{array}{c}\text { DJF } \\
\text { precipitation }\end{array}$ & $\begin{array}{c}\text { NS DJF } \\
\text { correlation }\end{array}$ & $\begin{array}{c}\text { SEE DJF } \\
\text { correlation }\end{array}$ & $\begin{array}{c}\text { JJA } \\
\text { precipitation }\end{array}$ & $\begin{array}{c}\text { NS JJA } \\
\text { correlation }\end{array}$ & $\begin{array}{c}\text { SEE JJA } \\
\text { correlation }\end{array}$ \\
\hline NS & 497.3 & $\mathbf{1}$ & 0.13 & 327.3 & $\mathbf{1}$ & 0.21 \\
SS & 410.6 & $\mathbf{0 . 8 8}$ & $\mathbf{0 . 3 2}$ & 299.3 & $\mathbf{0 . 7 5}$ & $\mathbf{0 . 4 8}$ \\
ES & 200.8 & $\mathbf{0 . 4 4}$ & $\mathbf{0 . 6 5}$ & 204.2 & $\mathbf{0 . 5 0}$ & $\mathbf{0 . 6 5}$ \\
NI & 286.9 & $\mathbf{0 . 5 2}$ & $\mathbf{0 . 5 7}$ & 251.3 & $\mathbf{0 . 5 6}$ & $\mathbf{0 . 6 2}$ \\
NWE & 278.0 & $\mathbf{0 . 6 7}$ & $\mathbf{0 . 6 1}$ & 245.6 & $\mathbf{0 . 5 0}$ & $\mathbf{0 . 6 7}$ \\
NEE & 207.6 & 0.11 & $\mathbf{0 . 7 9}$ & 200.4 & $\mathbf{0 . 3 1}$ & $\mathbf{0 . 7 1}$ \\
SWE & 314.5 & $\mathbf{0 . 3 4}$ & $\mathbf{0 . 9 1}$ & 212.8 & $\mathbf{0 . 4 3}$ & $\mathbf{0 . 8 1}$ \\
CE & 158.9 & 0.05 & $\mathbf{0 . 9 0}$ & 175.6 & 0.20 & $\mathbf{0 . 8 9}$ \\
SEE & 198.0 & 0.13 & $\mathbf{1}$ & 168.4 & 0.21 & $\mathbf{1}$
\end{tabular}

\footnotetext{
Sibley A, Cox D, Titley H. 2015. Coastal flooding in England and Wales from Atlantic and North Sea storms during the 2013/2014 winter. Weather 70(2): $62-70$.

Svensson C, Brookshaw A, Scaife A, Bell V, Mackay J, Jackson C, Hannaford J, Davies H, Arribas A, Stanley S. 2015. Long-range forecasts of UK winter hydrology. Environmental Research Letters 10(6): 064006, doi: 10.1088/1748-9326/10/6/064006.

Turnpenny JR, Crossley JF, Hulme M, Osborn TJ. 2002. Air flow influences on local climate: comparison of a regional climate model with observations over the united kingdom. Climate Research 20(3): 189-202, URL http://www.jstor.org/stable/24866806.

Wallace J, Lau NC. 1985. On the role of barotropic energy conversions in the general circulation. Advances in geophysics 28: 33-74.

Weston KJ, Roy MG. 1994. The directional-dependence of the enhancement of rainfall over complex orography. Meteorological Applications 1(3): 267-275.

Wilby R, O'Hare G, Barnsley N. 1997. The north atlantic oscillation and british isles climate variability, 1865-1996. Weather 52(9): 266-276.

Wilks DS. 1995. Statistical methods in the atmospheric sciences. Academic Press.

Woollings T, Hannachi A, Hoskins B. 2010. Variability of the north atlantic eddy-driven jet stream. Quarterly Journal of the Royal Meteorological Society 136(649): 856-868, doi:10.1002/qj.625.
} 
Table 2: Regression coefficients for the estimated precipitation anomaly in each region, as given by equation 1 . Values in italics are those that fail the significance testing $(p>0.1)$ so are set to zero in the regression equation.

\begin{tabular}{lcc}
\hline Region & $\alpha$ & $\beta$ \\
\hline NS & -21.31 & 106.32 \\
SS & -26.73 & 70.81 \\
ES & -31.40 & 6.45 \\
NI & -34.69 & 14.80 \\
NWE & -42.74 & 31.27 \\
NEE & -38.33 & -8.00 \\
SWE & -71.87 & 16.41 \\
CE & -37.08 & -6.04 \\
SEE & -56.11 & 0.60
\end{tabular}

Table 3: Brier skill scores for precipitation in each HadUKP region obtained from GloSea5 hindcasts of MSLP using the linear regression method, for the period 1992-2011. The two columns show the unadjusted and RPC-adjusted forecasts.

\begin{tabular}{lcc}
\hline Region & Uncorrected & RPC-corrected \\
\hline NS & 0.21 & 0.36 \\
SS & 0.14 & 0.28 \\
ES & -0.04 & -0.16 \\
NI & 0.14 & 0.25 \\
NWE & 0.21 & 0.33 \\
NEE & 0.13 & 0.14 \\
SWE & 0.05 & -0.04 \\
CE & 0.13 & 0.19 \\
SEE & 0.13 & 0.09
\end{tabular}

